\title{
Coordination Exercise for 10 Year Old Beginner Tennis Players
}

\author{
Gumilar Mulya ${ }^{1}$, Resty Agustryani ${ }^{1}$ \\ ${ }^{1}$ Pendidikan Jasmani, Kesehatan, dan Rekreasi-Universitas Siliwangi
}

\begin{tabular}{|c|c|}
\hline ARTICLE INFO & ABSTRACT \\
\hline Article History: & $\begin{array}{l}\text { Abstract: There are many forms of training to improve the quality of physical condition } \\
\text { of the tennis court athletes, one of which is coordination training. Thus, the author would }\end{array}$ \\
\hline $\begin{array}{l}\text { Received: } 21-01-2020 \\
\text { Approved: } 15-04-2020\end{array}$ & $\begin{array}{l}\text { like to try applying various forms of coordination exercises that are applied to children } \\
\text { aged } 10-11 \text { years who participate in tennis clubs in the City of Tasikmalaya to support }\end{array}$ \\
\hline $\begin{array}{l}\text { Key Words: } \\
\text { coordination exercise; } \\
\text { beginner; } \\
\text { tennis }\end{array}$ & $\begin{array}{l}\text { hand coordination. The aim of this research is to find out eye-hand coordination in } \\
\text { elementary school students. The focus of this research is limited to the effectiveness of } \\
\text { Coordination to support good physical condition in children. This research used } \\
\text { experimental research methods. The population in this research were all } 30 \text { children who } \\
\text { joined the tennis club in Tasikmalaya City. The sampling technique used is the total } \\
\text { sampling technique. In order to get objective data, the author uses a measuring instrument } \\
\text { in the form of a test that is eye-hand coordination test. Based on the results of this research } \\
\text { and statistical calculations on the data obtained in this research, the authors can conclude } \\
\text { that coordination exercises have a significant influence on improving eye-hand } \\
\text { coordination especially for beginner tennis players of elementary school age. }\end{array}$ \\
\hline
\end{tabular}

\author{
Correspondence: \\ Gumilar Mulya \\ Pendidikan Jasmani, Kesehatan, dan Rekreasi \\ Universitas Siliwangi \\ Jalan Siliwangi 24 Tasikmalaya \\ E-mail: gumilarmulya@unsil.ac.id
}

Tennis is a sport that is usually played by two players or by two pairs of players. Each player uses a racket to hit a rubber ball. The aim of the game is to play the ball in a certain way so that the opposing player cannot return the ball. The basic principle of playing tennis is to hit the ball over the net and land in the opponent's playing area. The ball is hit as far as possible from the opponent's reach, making it difficult for the opponent to hit and return the ball. The mastery of the basic techniques of doing good and correct hits is very important. Tennis is a sport that has changed markedly over the last few decades because supporting technology for sports has developed very rapidly and training has improved considerably. Coordination, agility and speed are not some of the most important physical components that can support success in every tennis match. Training for coordination, speed and special agility of tennis are arranged in a form of movement, time and distance covered in numbers. Tennis movements are very specific to certain situations, and are carried out in reactive situations (Kovacs, 2007). Although all players have some things that are consistent, the tennis movement is very specific to each tennis player's position on the field.

There is an age-based classification for Tennis young players. The age group in tennis ranges from $7-12$ years. According to (Bompa and Buzzichelli, 2015), beginner players are 7-8 years of age both for male and female, while specialized players are 11-13 years of age for females and 12-14 years of age for males. Annarino, Cowell, and Hazelton (1980) described some of the characteristics of children aged 9-10 years (grades 3 and 4). The physiological characteristics of children aged 910 years include: (a) improved basic motion coordination; (b) increased endurance; (c) strong physical growth; (d) good eye and hand coordination; (e) unimproved body posture; (f) the female's physiology is a year ahead of males; (g) shedding of deciduous teeth and replaced by permanent teeth; (h) gender differences have not yet influential; (i) individual differences become more apparent; and (j) high tendency of injury due to their mobility. The psychological characteristics include: (a) broader scope of their attention, developed curiosity of achievement; (b) improved thinking ability; (c) having a liking for fantasizing, music, and rhythmic movements; (d) imitative of idol figures; (e) more interest in organized games increase; (f) strong desire to be like an adult; $(\mathrm{g})$ enjoy repeating activities; and (h) likes competitive activities. The statement clearly shows that the complexity of the abilities of 10-year-olds is very high. Therefore, all components of the physical condition must be shaped at an early age so that they become the physical foundation in the future. On one hand, children learn and develop easily, and on the other hand, they are easily disturbed if they are mistreated even the slightest.

Tennis is a sport that highly demands the component of physical condition since it determines how well a technical movement is done. The bio motor components needed in playing tennis are power, speed, endurance, agility, flexibility, and coordination (Mandlikova and Stove, 1990). Similarly, Erman, Sahan, and, Küçükkaya (2013) emphasized that tennis sports really require many different bio motor characteristics such as neuromuscular strength, strength, endurance, agility, balance, and handeye coordination. The physical condition program must be fully designed to meet the demands of sports performance and it is 
crucial in tennis. This is in line with the (Chandler, 1995) that "Tennis is a sport that requires extra physical activity. A complete physical condition program designed to meet the demands of the sport and the muscle abilities of individual players is important in tennis, especially at the junior to professional level." This research investigated a basic physical component namely coordination.

The important role of vision and responsive movements is needed in this tennis sport, coordination cannot be done well if the views and movements are not supportive. Coordination can be defined as the harmony of motion of a group of muscles as long as the appearance of the motion produces a skill (Kirkendall, Gruber, and Johnson, 1987). Mutohir and Maksum (2007) explained that coordination is the body's ability to integrate different movements into a single harmonious and effective movement. Coordination is an integral part of motor skills, so the notion of coordination as an equivalent of motor skills and skills. Coordination has varying degrees of difficulty in making a move that is fast, efficient, full accuracy and stimulating muscle performance when someone stops the excitatory that is opposite to that muscle. Coordination is the ability of biomotoric and complex basic movements to carry out sequences of movements smoothly and accurately by involving the senses, muscle contractions, the use of feelings, vision, hearing together from parts of the body and is associated with a series of muscle contractions that affect the combined limbs and position the body in displaying motion smoothly and precisely. Kurz, Anders, Walther, Schenk, and Scholle (2014) explains that Coordination is the ability to perform varying degrees of difficulty of movement very quickly and with efficiency and accuracy. athletes who have qualified coordination are not only able to perform skills well, but also can do it quickly in completing training task.

The coordination skills needed in tennis are eye coordination and arm movements when hitting the ball. Eye-hand coordination shows the ability to learn selecting objects around the person and to coordinate the objects in view and movement manipulations. The eye-hand coordination activity requires precision and movement control. The results of a stroke technique in tennis are strongly influenced by good eye-hand coordination ability. This is the result of a research by (Predoiu, 2015) which showed that two handed backhand stroke is not more effective than one handed backhand stroke, with respect to targeting in tennis and two hand-eye coordination abilities. By looking at the course of the ball, the direction and position of the fall of the ball will be predicted, so that the player can take the correct position to hit the ball with the appropriate setting between the fall of the ball and the length of reach. In the matter of Tennis practice, it is important to have not only the skill to see the ball, but also the ability to see where the ball will be hit. Based on the observations, in carrying out stroke movement technique using footwork, children tend to be rigid, therefore the provision of coordination training is to improve the ability to master motion. Without having good coordination skills, athletes will have difficulty in performing techniques in a harmonious and simultaneous manner. In tennis, vision is part of the main component, because seeing the movement of the opponent and the direction of the ball that is constantly changing is a particularly difficult and it must be done with eye observation. This is in accordance with (Maman, Gaurang, and Sandhu, 2011).

The sense of sight is perhaps the most variable and selective of all the senses. Trying to observe a movement quickly that occurs in sports venues is very popular among the public. Vision in tennis, is the deciding factor. It is also stated by (Paul, Biswas, and Sandhu, 2011) that tennis has long been practiced to train visual activities and special coordination for other sports but the sport itself is ignored because of the specificity of the training; which is the main factor that determines sports training. It is very clear that sensory and motoric have a positive relationship to support achievement. Visual sensory input can reach up to 85-90\% of an athlete's sensory input during an athletic match (Zupan, Arata, Wile, and Parker, 2006). Being the first step of the vision of information processing forms an important component of successful sports performance. Thus, the athlete's ability to vary his visual determinants and coordinated movements in the task of interception adds to his skills. With regard to the distinctive role of vision in sports, there have been claims that the use of visual training programs can be productive on player performance. In line with these claims, the results of this study show a significant increase in visual variables for the experimental group. This finding is consistent with the literature reviewed by Cohen (1988) which revealed that a constructive visual training program improves visual skills in athletes. Improved visual ability in relation to a person's motor learning behavior, which involves learning new skills and even refining existing skills with repetition. In connection with this principle, the continuous repetition of sight exercises and structured tasks leads to an increase in the variable of visual skills. Kawai, et al (2015) states that movement skills or motor skills are a successful motor skills training that require a long and repetitive training period.

After all the skills can be mastered, all of them just need to be well-memorized for a long period of time. Good memory promotes good opportunity for motor skills training. To achieve a better understanding, one of the efforts of scientific study is to thoroughly explore the learning process into several parts and how it interacts. This research reveals the fact that motor skills training can be successful because of gradual learning. The acquisition phase is marked quickly (in training sessions) and slow training (between training sessions). During training and also at rest, activation in various regions of the brain changes dynamically. facts for the stages in learning motor skills are provided by experiments using behavior, electrophysiology, functional imaging, and cellular/molecular methods. Therefore, this eye-hand coordination must be given special attention in addition to several other physical conditions. 


\section{METHOD}

Referring to the purpose of this study, the research method used in is an experimental research method. Experimental research aims to find out the differences in the treatment of others in controlled conditions. A controlled condition in intention is that the research results are converted into numbers, for the analysis used by statistical analysis (Sugiyono, 2008). The research was carried out by providing training programs to elementary school students in Sumedang Regency. The design used in this study was "Pre-test and Post-test Design", the subjects in this study were a number of elementary school students who were members of a club in the City of Tasikmalaya with a total of 30 children, aged 10-aged 11 years. The test used was eye-hand coordination tests (Kirkendall, Gruber, Johnson, 1987). This research includes visuo-motor parameters which are very important for playing tennis any level. Data before and after training were collected from the following parameters. Before testing procedures, subjects get acquainted with equipment and testing, and undergo several training sessions. The measurement of the eye-hand coordination was done by the following procedure. The testee (sample) stood behind a boundary line holding the ball. When the tester signals the start, the testee performed an overhead throw to a target wall as many times as possible with a time limit of 15 seconds. The ball could be hit in flight or after bouncing to the floor. If the ball went off of the throwing area, then the teste picked up the ball by himself. When there was a stop signal, then the testee must stop the throw. The legitimate throws were counted as the eye-hand coordination score. Coordination exercises given to these children were games such as catch the ball inside the ladder, balance touch cones, between the legs, catch with carioca, jump rope box one leg, non-dominant warm ups and so on.

The sample group in this study underwent eye and hand coordination training for approximately 8 weeks, the details of which were 3 days a week combined with technical training as usual. Each session lasts for 40 minutes. Systematic training in athletes involves the following procedures:

1) forms of visual exercises such as swing balls, with exercises using footwork sensors to practice concentration when given visual signal training (Revien and Gabor, 1981).

2)Hand-eye coordination training: Hand-hand coordination training is conducted. During the training process, participants are given a tennis ball, then bounced off the wall, having to change hands when catching the tennis ball.

\section{Data Analysis}

Data analysis Data were obtained from tests that were explained and analyzed using Statistics (SPSS)/17.0. Each eyehand coordination performance variable is analyzed to determine whether there are significant differences between the scores before and after training and whether these changes are influenced by specific training conditions. The statistical test used to analyze this study was paired with a t-test.

\section{RESULT \& DISCUSSION}

Good technical skills in sports branch are always developed along with the higher demands of achievement. Therefore, each individual needs to develop technical training. Training in developing technical skills means developing the ability to coordinate muscle nerve functions Sukadiyanto \& Muluk (2011) explained that biomotor components of coordination are needed in almost all matches and competitions, because the basic elements of motion techniques in sports involve synchronization of several abilities. A tennis player must be able to coordinate between the eyes and the hands, hence the movement tasks that were carried out, especially when hitting the ball, were expected to improve eye-hand skills. The movements were easy, quick, and controlled. In the end it will produce a fast, easy, and directed stroke, making it difficult for the opponent to control the ball. Table 1 presents the distribution of eye-hand coordination test scores.

\section{Table 1. Distribution of the Participants' Eye-Hand Coordination Pretest and Posttest Scores}

\begin{tabular}{clc}
\hline No & \multicolumn{1}{c}{ Characteristic } & Score \\
\hline 1 & Pretest Score & \\
& Mean & 8.14 \\
& SD & 4.34 \\
2 & Posttest score & \\
& Mean & 10.12 \\
& SD & 2.21 \\
\hline
\end{tabular}

Table 1 presents the average score of eye-hand coordination before the treatment is 8.14 with SD 4.34. After the treatment, the average score is 14.12 with SD 2.21. The coordination changes were measured using eye-hand coordination tests and the results were continuum data. 


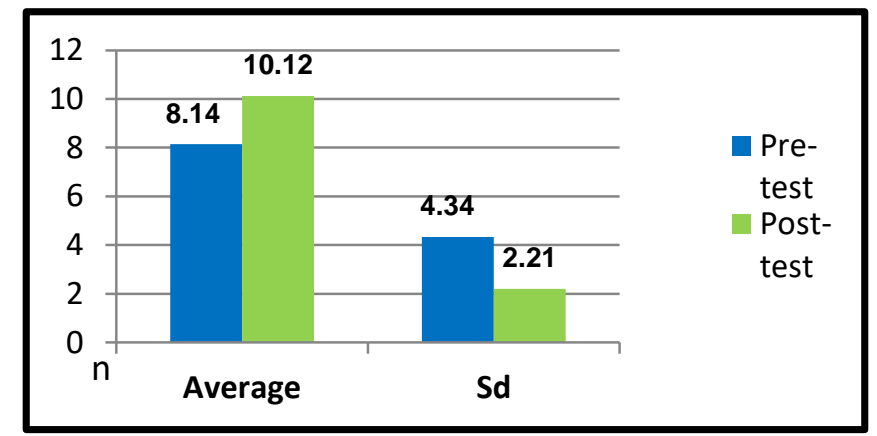

Figure 1. Diagram Eye-Hand Coordination Pretest and Posttest Scores

\section{Results of Normality Test}

The data normality test used in this research is Liliefors statistical test. The results of each test are presented in table 2.

Table 2. Results of Eye-Hand Coordination Data Normality Test

\begin{tabular}{cccc}
\hline Test group & L $_{\text {count }}$ & L table & Result \\
\hline Pretest & 0.120 & 0.161 & Normal \\
Posttest & 0.078 & 0.161 & Normal \\
\hline
\end{tabular}

Based on the tables, it can be seen that $\mathrm{L}_{\text {count }}\left(\mathrm{L}_{0}\right)$ was smaller than $\mathrm{L}_{\text {table }}$ at 0.05 significance level, which means the data was normally distributed.

\section{Results of Hypothesis Testing Using $t$ Test}

Since the data from each test was normally distributed, then the hypothesis testing used was one-sample test ( $\mathrm{t}$ test). In testing the hypothesis, the criteria for the $t$ value was based on the $t$ value distribution table. The results is presented in the following table 3 .

\section{Table 3. Results of Hypothesis Testing Using t Test}

\begin{tabular}{cccc}
\hline Test Group & $\mathrm{t}_{\text {count }}$ & $\mathrm{t}_{\text {table }}$ & Result \\
\hline Sample & 10.113 & 1.697 & Significant \\
\hline
\end{tabular}

Based on the list of tables above, it can be seen that the value of the $t_{\text {count }}$ at 0.05 significance level was outside the interval $\left(t_{\text {count }}>t_{\text {table }}=10.113>1.697\right)$. Then from these data, it is known that there were significant differences in the sample group after they were given the coordination training.

This research has outlined the amount of physical quality and coordination with the scope of several factors that can have a strong impact on tennis performance at the age of 10 to 12 years. This shows that at a young age, the children tried to participate in a sport that emphasizes the importance of mastery of movements. Therefore, there were several reasons why the children were unable to carry out a series of stroke techniques and eye-hand coordination. First, it is due to their concentration which was often uncontrollable which could be the result of a variety of exhausting exercises. Concentration is an important factor, this is in accordance with Mosoi (2013) that the player's concentration can be considered as an important element in sport. The duration and the level of attention and concentration can be observed as being important factors in the game of tennis. In principle, if coordination is carried out more seriously with high concentration, it can be handled well since the eye-hand coordination has key role to success in tennis (Sahan and Erman, 2009). Moreover, to be able to see the movement of the ball and make a deadly stroke towards the opponent, it is necessary to have good eye-hand coordination. This is in line with Sahan and Erman (2009) that as the way the ball impacts the racket and the ball speed can change, the hand-eye coordination gets more important.

In a tennis match, the average acquisition figure is made in less than 10 seconds (Enoka, 2008). Recovery from one place to another is usually between 20 and 25 seconds. The player makes an average of four changes in direction per point, but movements at certain points can range from one movement to more than 15 changes in direction during long rallies. In matches, it is not uncommon for players to make more than a few changes in place. About $80 \%$ of all punches are played in distances of less than 8 meters $(7 \mathrm{~m})$. Less than 5 percent of hits are played that require more than 15 feet $(5 \mathrm{~m})$ between beats (Callan, Brunner, Devolve, Hesson, Wilber, and Kearney, 1998). It is interesting to note that tennis players can cover around $30-60 \mathrm{~cm}$ more on their forehand side than on their backhand side (Lin, Liu, Lin, Tsai, and Chao, 2008). The results of this study are very helpful when developing a motion training program especially for tennis, because tennis players may need to practice a little further on the forehand side. This is an important finding, because most speed and agility programs for other sports focus on longer distances 
than those seen in tennis. They have never experienced maximum speed when running during the match limit. Unlike many other sports, most tennis movements are in the lateral direction. Studies show that the movements of professional tennis athletes find that more than $70 \%$ of movements are carried out from side to side, with less than $20 \%$ of movements in linear, forward, linear, and less than $8 \%$ of movements in linear, backward, linear directions (Lin, Liu, Lin, Tsai, and Chao, 2008). is very important because the acceleration and deceleration of distance described previously is a major determining factor in tennis movements. Linear acceleration, maximum linear velocity, and agility are separate and different biomotor skills that need to be trained separately because training one biomotor skill does not directly affect the improvement of another. There will be no speed and agility without the support of good coordination. Therefore, tennis players should focus between $60-80 \%$ of their training time on lateral movements, $10-30 \%$ on forward movements, and only about $10 \%$ on backward movements. Another thing that can have a direct effect on how fast players can move in short distances is their reaction time.

Reaction time is the time between when the stimulus is detected (visual awareness of the stroke or the opposing ball) and the force generated (Koch, et al, 2003). Although the reaction time does not correlate well with sprints that last longer than a few seconds, it correlates very well with the distance that is usually seen in tennis matches (Haywood and Getchell, 2019). Therefore, tennis athletes must be able to practice continuously to increase reaction time along with other tennis movements, such as technique, strength, and strength. In training, the trainer must use visual stimulation, because the type of stimulation that must be given to tennis players in the form of vision rather than sound stimulation (whistle, voice, or clapping) is less specific for tennis in helping athletes develop their reaction time. Rotation is a major component of tennis-specific movements. Movement that combines these skills must be used in speed and agility training. Many of the exercises described in this study can be made more specific by adding rotation (through the use of a medicine ball or tennis punch) during many directional movements. An example is doing exercises using a tennis racquet.

Tennis is a situational sport where the outcome of a match is directly affected by interactions with opponents. In fact, athletes must respond in a short time to change how they play by analyzing the speed, rotation, and direction of tennis balls quickly. Because of this, it is very complicated to predict exactly what will happen during matches and matches. because both the opponent and the athlete themselves always use tactics or strategies that might not be the same in every game. According to the literature, if an athlete has good visual skills, then players can receive and process information quickly and can optimize performance with exceptional accuracy and agility. For this reason, training must aim to increase reaction time, through good coordination exercises as well. During each change of direction, the athlete can mimic the forehand or backhand, or even volley. Some very useful exercises in this study include the lateral line jumps and the 180 degree trajectory crossing of the line training section and lateral shaking, proagility drill, T-drill, and attack drill and retreat from the conical drill section. the following suggestions can help when training specific tennis agility and speed for good coordination:

1) Reactive training is the goal of a special speed and agility program for players.

2) Lateral training is very necessary because it is the biggest factor during the training period.

3) Short distance training by mimicking the demanding movements of athletes leads to a very effective program.

4) The coach must be able to design a footwork program so that he can track the movement patterns of each player during the match and can arrange the program individually based on their observations.

5) Athletes should only add endurance training to their training after perfecting the techniques and mechanics of the movement and maintaining or increasing power.

6) Technical training with slow motion but aiming to improve techniques is very important to help tennis athletes move more efficiently on the field, and to reduce the chance of injury.

7) Improved achievements in various sensory and motor skills exercises can be channeled into performance during competitive sports. Study In this study a significant increase in post-training performance was observed for the research group. Improvement indicates an increase in performance evaluation scores. According to the basic principle of specificity, this increase can be attributed to visual training as in this study visual skills are very important for tennis players during practice and competition. in this study there were no novice players involved in this study, who had specific prior visual training experience so that visual skills training was very rarely sampled. Therefore the samples did a coordination exercise interspersed with movement exercises with footwork tools.

\section{CONCLUSION}

The results of the data show that there is an increase in this study showing that the application of variations in coordination exercises by combining the agility movement in each of the training presentations, in fact can have a significant effect on improving eye-hand coordination, especially in elementary school beginners. This is indicated by an increase in the average score and an increase in scores between the pretest before being given the training program and the posttest after being given the training program. Although the improvement is not that big, it shows that coordination training can improve coordination, especially eye-hand coordination in novice athletes aged $10-11$ years. this can be a reference material for every trainer, in order to always provide coordination exercises combined with several elements of other physical condition components, so that athletes can learn one movement, techniques with coordination and excellent physical condition. 


\section{REFERENCES}

Annarino, A. A., Cowell, C. C., \& Hazelton, H. W. (1980). Curriculum Theory and Design in Physical Education. Mosby. Bompa, T., \& Buzzichelli, C. (2015). Periodization Training for Sports, 3E. Human Kinetics.

Callan, S. D., Brunner, D. M., Devolve, K. L., Mulligan, S. E., Hesson, J., Wilber, R. L., \& Kearney, J. T. (2000). Physiological Profiles of Elite Freestyle Wrestlers. The Journal of Strength \& Conditioning Research, 14(2), 162-169.

Chandler, T. J. (1995). Exercise Training for Tennis. Clinics in Sports Medicine, 14(1), 33-46.

Cohen, A. H. (1988). The Efficacy of Optometric Vision Therapy. Journal of the American Optometric Association, 59(2), 95105.

Enoka, R. M. (2008). Neuromechanics of Human Movement. Human Kinetics.

Erman, K. A., Şahan, A., \& Küçükkaya, A. (2013). The Effect of One and Two-Handed Backhand Strokes on Hand-Eye Coordination in Tennis. Procedia-Social and Behavioral Sciences, 93, 1800-1804.

Haywood, K. M., \& Getchell, N. (2019). Life Span Motor Development. Human Kinetics.

Iacoboni, M. (2001). Playing Tennis with The Cerebellum. Nature Neuroscience, 4(6), 555-556.

Kawai, R., Markman, T., Poddar, R., Ko, R., Fantana, A. L., Dhawale, A. K., ... \& Ölveczky, B. P. (2015). Motor Cortex is Required for Learning but not for Executing a Motor Skill. Neuron, 86(3), 800-812.

Kirkendall, D. R., Gruber, J. J., \& Johnson, R. E. (1987). Measurement and Evaluation for Physical Educators.

Koch, A. J., O'BRYANT, H. S., Stone, M. E., Sanborn, K., Proulx, C., Hruby, J., ... \& Stone, M. H. (2003). Effect of Warm-Up on the Standing Broad Jump in Trained and Untrained Men and Women. The Journal of Strength \& Conditioning Research, 17(4), 710-714.

Kovacs, M. S. (2007). Tennis Physiology. Sport Medicine, 37(3), 189-198. Kurz, E., Anders, C., Walther, M., Schenk, P., \& Scholle, H. C. (2014). Force Capacity of Back Extensor Muscles in Healthy Males: Effects of Age and Recovery Time. Journal of Applied Biomechanics, 30(6), 713-721.

Lin, J. D., Liu, Y., Lin, J. C., Tsai, F. J., \& Chao, C. Y. (2008). The Effects of Different Stretch Amplitudes on Electromyographic Activity During Drop Jumps. The Journal of Strength \& Conditioning Research, 22(1), 32-39.

Maman, P., Gaurang, S., \& Sandhu, J. S. (2011). The Effect of Vision Training on Performance In Tennis Players. Serbian Journal of Sports Sciences, 5(1).

Mandlikova, H., \& Stove, B. (1990). Total Tennis: A Guide to the Fundamentals of the Game. Simon \& Schuster Australia.

Mosoi, A. A. (2013). Psychological and Motor-Coordination Factors in Children Tennis Players. Procedia-Social and Behavioral Sciences, 78, 220-224.

Mutohir, T. C., \& Maksum, A. (2007). Sport Development Index, Alternatif Baru Mengukur Kemajuan Pembangunan Bidang Keolahragaan. Jakarta: PT Indeks.

Paul, M., Biswas, S. K., \& Sandhu, J. S. (2011). Role of Sports Vision and Eye Hand Coordination Training in Performance of Table Tennis Players. Brazilian Journal of Biomotricity, 5(2), 106-116.

Predoiu, R. (2015). Intersegmental and Eye-Hand Coordination in Elite Junior Tennis Players. Procedia-Social and Behavioral Sciences, 187, 107-112.

Revien, L., \& Gabor, M. (1981). Sportsvision: Dr. Revien's eye exercise program for athletes. Workman Pub Co.

Sahan, A., \& Erman, K. A. (2009). The effect of the Tennis Technical Training on Coordination Characterictics. The Open Sports Medicine Journal, 3(1), 59-65.

Sugiyono. (2008). Metode Penelitian Pendidikan:(Pendekatan Kuantitatif, Kualitatif dan R \& D). Bandung: Alfabeta.

Sukadiyanto., \& Muluk, D. (2011). Pengantar Teori dan Metodologi Melatih Fisik. Bandung: Lubuk Agung.

Zupan, M. F., Arata, A. W., Wile, A., \& Parker, R. (2006). Visual Adaptations to Sports Vision Enhancement Training. Optometry Today, 1, 43-48. 